\title{
Tube-fin Heat Exchanger Circuitry Optimization For Improved Performance Under Frosting Conditions
}

\author{
Zhenning $\mathrm{Li}^{1} \quad$ Hongtao Qiao $^{2} \quad$ Vikrant Aute $^{3 *}$ \\ ${ }^{1,3}$ Center for Environmental Energy Engineering, University of Maryland \\ College Park, MD 20742 USA \\ ${ }^{2}$ Mitsubishi Electric Research Labs, 201 Broadway Cambridge, MA 02139 USA
}

\begin{abstract}
Frost accumulation on tube-fin heat exchanger leads to reduction in evaporator capacity and deteriorates cycle efficiency. The conventional counter-flow heat exchanger circuitry has the disadvantage that more frost tends to accumulate in the first few banks exposed to the incoming air. This frost concentration makes the air side flow resistance increase rapidly, thus reduces the air flow rate and evaporator capacity under constant fan power. In this paper, a novel integer permutation based Genetic Algorithm is used to obtain optimal circuitry design with improved HX performance under frosting conditions. A dynamic HX model with the capability to account for non-uniform frost growth on a fan-supplied coil is used to assess the performance of optimal circuitry. The case study shows that the proposed circuitry design approach yields better circuitry with larger HX capacity, more uniform frost distribution, less air flow path blockage, and therefore longer evaporator operation time between defrost operations.
\end{abstract}

Keywords: Heat Exchanger, Frost Growth, Circuitry Optimization, Genetic Algorithm

\section{Introduction}

Tube-fin heat exchangers have wide applications in the refrigeration and air conditioning industry. They are used to transfer heat between air and the working fluid (e.g. refrigerants, water, glycols etc.). One of the major concerns for the refrigeration and heat pump engineers is frost formation on outdoor unit since it can lead to significant reduction on heat exchanger capacity and cycle efficiency.

Frost will accumulate on the surfaces of evaporator coil when the coil surface temperature is below the dew point temperature of incoming air and meanwhile the air dry bulb temperature is below $0{ }^{\circ} \mathrm{C}$. The process of frost formation on the surface of an evaporator coil is a result of two mechanisms: the buildup of small ice particles that exist in the free air stream and accumulate by impaction or interception when they contact the evaporator coil surfaces (Malhammar, 1988) and the diffusion of water vapor onto cold surfaces due to the water vapor concentration difference between the air stream and the frost layer surface (Sanders, 1974).

Formation of frost on a heat exchanger surface results in reduction on heat transfer rate due to fouling characteristics of frost development and blockage of air flow passages through the heat exchanger. Several techniques have been proposed to reduce the frost accumulation rate thereby increasing the evaporator operation time between defrost operations. For example, (Ogawa et al, 1993) suggested to use variable geometry tube-fin heat exchangers with different fin geometries on different tube banks to reduce the heat and mass transfer rates at the first few banks exposed to incoming air. However, this geometry modification may be difficult to realize without adding substantial complexity in manufacturing process. (Aljuwayhel et al, 2007) developed a heat exchanger frost accumulation model to simulate the performance of counter-flow and parallel-flow circuitry evaporators under frosting conditions. They validated the model by testing the counter-flow circuitry evaporator. They found that heat exchanger circuitry can influence the frost distribution across the evaporator as well as its transient capacity under frosting conditions. Their study shows good circuitry design is a convenient and economic way to reduce the effect of frost accumulation and can provide longer evaporator operation time before defrosting.

As discussed in ( $\mathrm{Li}$ et al, 2018), various performance metrics have been used as objectives for the TFHX circuitry optimization studies, however, in literature there is no study which optimizes circuitry with the goal of improving HX performance under frosting conditions. This paper presents a tube-fin heat exchanger circuitry design approach to tackle this problem.

The remainder of the paper is organized as follows: section 2 details the circuitry optimization approach and analyzes the optimization results from a case study. Section 3 introduces the dynamic HX model with integrated frosting growth model and then demonstrates the efficacy of the proposed circuitry design approach by evaluating the dynamic performance of different 
circuitry designs under frosting conditions. Conclusions are drawn in Section 4.

\section{TFHX Circuitry Optimization}

\subsection{Integer Permutation Based GA}

An integer permutation based genetic algorithm (IPGA) developed by ( $\mathrm{Li}$ et $a l, 2018)$ is used to obtain the optimal circuitry designs. (Li and Aute, 2018) has shown that IPGA demonstrates superior capability to obtain better refrigerant circuitries with lower computational cost than the other methods in literature. Meanwhile IPGA can guarantee good manufacturability of resulting circuitries.

Usually, the dynamic simulation of HX performance under frosting conditions is computationally expensive, which means the computational time for a single simulation can take from a few minutes to several hours. Assuming one HX evaluation takes a few minutes to complete, as there will be at least thousands of HX evaluations in one optimization run, using dynamic HX model to evaluate HXs generated by the optimizer is not feasible in the interests of time. This study strives to tackle this problem by exploring an effective problem formulation used in steady state HX optimization in order to generate circuitry designs with desirable dynamic performance under frosting conditions.

At the fitness assignment stage of IPGA, a mass flow based steady state tube-fin heat exchanger model, CoilDesigner $^{\circledR}$ (Jiang et al, 2006), is used to evaluate HX performance. This model can account for the refrigerant maldistribution among different circuits by iterating on the pressure residual at the outlet of each circuit.

\subsection{Problem Formulation}

As explained in previous session, the goal of this study is to explore a HX performance index which can foresee its dynamic performance under frosting conditions. (Qiao et al, 2017) observed that the tubes which the frost is the most likely to deposit on are the ones close to the refrigerant inlets with low HX surface temperature. In contrast, the tubes which the frost is the least likely to deposit on are the refrigerant outlet tubes where the intube refrigerant flow is superheated. Based on this finding, Equation (1) shows the problem formulation, in which to maximize the total length of superheat tube length is used as the objective. Five constraints are enforced on this problem. The 1st constraint guarantees that the optimal design has equal or larger capacity than the baseline. The 2 nd constraint limits that the optimal circuitry has less refrigerant pressure drop than the baseline with 1.1 as the relaxation factor. The 3rd constraint confines the outlet superheat of the entire coil to be similar with that of the baseline within $\pm 1 \mathrm{~K}$ variation. The last two constraints are manufacturability constraints. The $4^{\text {th }}$ constraint makes the inlet and the outlet tubes on the same side of HX. The $5^{\text {th }}$ constraint avoids long U-bends stretching across more than 2 tube rows. (Li and Aute, 2018) presents the details of various constraints and constraint handling techniques in IPGA.

Objective: Maximize(total superheat tube length)

Subject to :

$$
\begin{aligned}
& \mathrm{Q} \geq \mathrm{Q}_{\text {baseline }} \\
& \Delta \mathrm{P}_{\text {refrigerant }} \leq 1.1 \times \Delta \mathrm{P}_{\text {refrigerant,baseline }} \\
& \Delta T \text { sat }-1 K \leq \Delta T \text { sat } \leq \Delta T \text { sat }+1 K
\end{aligned}
$$

Inlets and outlets on the same side of HX

No long U-bend across more than 2 tube rows

\subsection{Baseline Outdoor Heat Exchanger}

An outdoor heat exchanger (Figure 1) from a flash tank vapor injection cycle (FTVI) is used as the baseline for circuitry optimization. The steady state heat exchanger model was validated with measured data for this coil in previous research project under different operating conditions (Xu et al, 2013). Figure 2 shows that the heat exchanger capacity deviations between CoilDesigner ${ }^{\circledR}$ simulations and experiments are within $6 \%$.

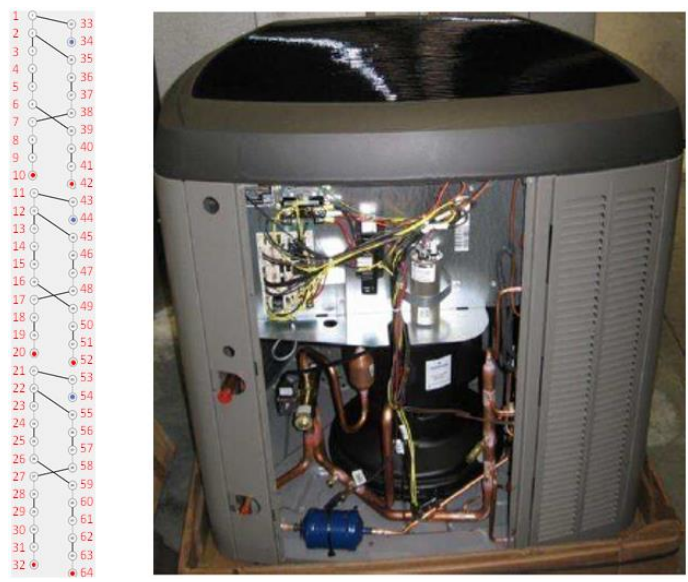

Figure 1. Outdoor unit from FTVI

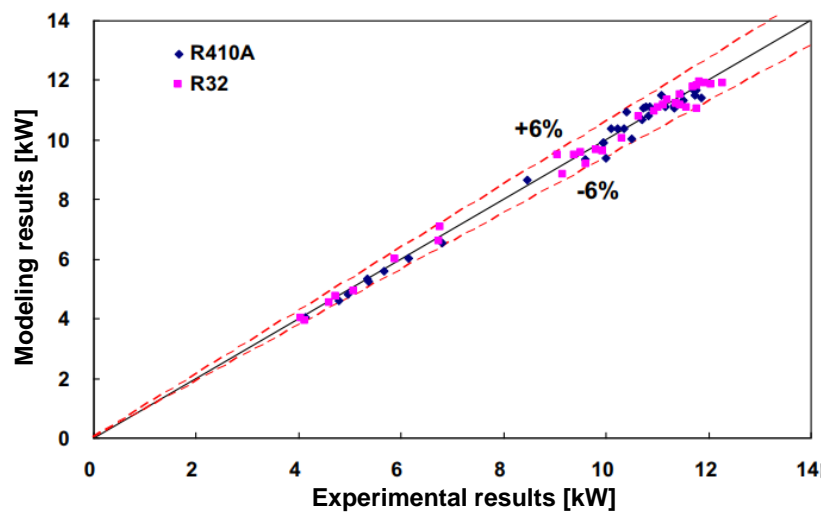

Figure 2. Experiment tests vs CoilDesigner ${ }^{\circledR}$ simulations

Table 1 lists the structural parameters of the baseline HX. Table 2 shows the operating conditions used in the steady state HX simulation. The air side condition is 
adopted from (ASHRAE, 2010) frost accumulation test. Table 3 lists the empirical correlations adopted for the local heat transfer and pressure drop calculations.

Table 1. Structural Parameters of Baseline Evaporator

\begin{tabular}{|l|l|}
\hline Structural Parameters & Value \\
\hline Tube Outer Diameter & $7.9 \mathrm{~mm}$ \\
\hline Fins per inch & 22 FPI \\
\hline Fin Type & Wavy Herringbone \\
\hline Tube Length & $2.565 \mathrm{~m}$ \\
\hline Vertical Spacing & $24.1 \mathrm{~mm}$ \\
\hline Horizontal Spacing & $20.9 \mathrm{~mm}$ \\
\hline Number of Tube Banks & 2 \\
\hline Number of Tubes Per Bank & 32 \\
\hline
\end{tabular}

Table 2. Operating Conditions of Baseline Evaporator

\begin{tabular}{|l|l|}
\hline Operating Conditions & Value \\
\hline Refrigerant & $\mathrm{R} 410 \mathrm{~A}$ \\
\hline Refrigerant Inlet Pressure & $636.3 \mathrm{kPa}$ \\
\hline Refrigerant Inlet Quality & 0.19 \\
\hline Refrigerant Mass Flow Rate & $0.035 \mathrm{~kg} / \mathrm{s}$ \\
\hline $\begin{array}{l}\text { Air Volume Flow Rate } \\
\text { (Uniformly Distributed) }\end{array}$ & $2267 \mathrm{ft}^{3} / \mathrm{min}$ \\
\hline Air Pressure & $101.325 \mathrm{kPa}$ \\
\hline Air Temperature & $1.7{ }^{\circ} \mathrm{C}$ \\
\hline Air Relative Humidity & $82 \%$ \\
\hline
\end{tabular}

Table 3. Correlations Adopted in HX Simulation

\begin{tabular}{|l|l|l|}
\hline $\begin{array}{l}\text { Operating } \\
\text { Mode }\end{array}$ & Heat Transfer & Pressure Drop \\
\hline $\begin{array}{l}\text { Refrigerant } \\
\text { Liquid Phase }\end{array}$ & Gnielinski, 1976 & Blasius, 1907 \\
\hline $\begin{array}{l}\text { Refrigerant } \\
\text { Two Phase }\end{array}$ & Shah, 2017 & $\begin{array}{l}\text { Müller- } \\
\text { Steinhagen \& } \\
\text { Heck, 1986 }\end{array}$ \\
\hline $\begin{array}{l}\text { Refrigerant } \\
\text { Vapor Phase }\end{array}$ & Gnielinski, 1976 & Blasius, 1907 \\
\hline Air & Kim et al, 1997 & Kim et al, 1997 \\
\hline
\end{tabular}

\subsection{Circuitry Optimization Results}

For the optimization practice conducted in this case study, the GA population size is set as 200 and the number of generations is set as 500. The GA progress plot (Figure 3) indicates that after 500 generations, the optimal circuitry yields an increase of total superheat tube length from $59.69 \%$ to $70.63 \%$ of the entire HX tube length.

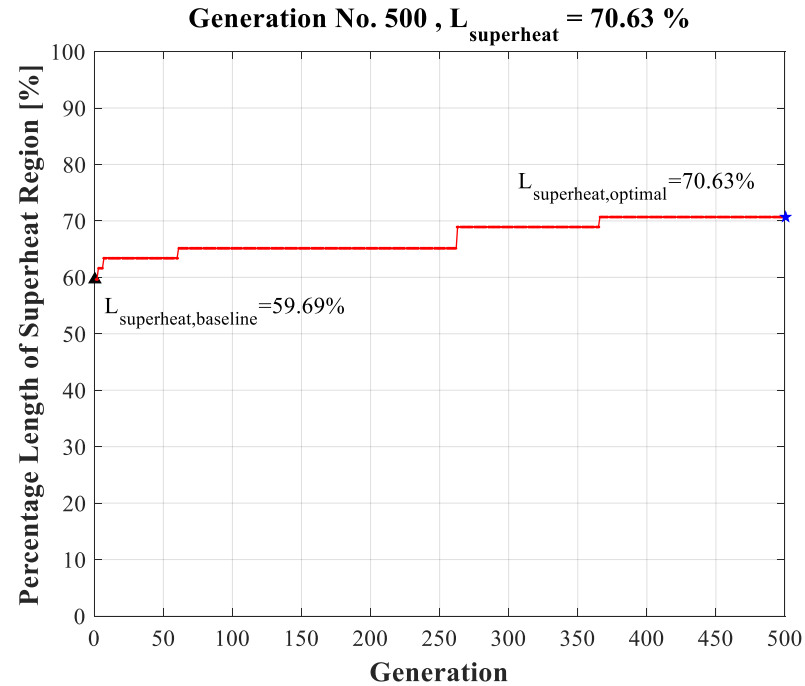

Figure 3. IPGA optimization progress

Figure 4 shows the optimal circuitry design after 500 generations. A solid line represents a U-bend on the front end of the heat exchanger, while a dotted line represents a U-bend on the farther end. Different color represents different circuits. The red tubes are the inlets, while the blue ones are outlets.

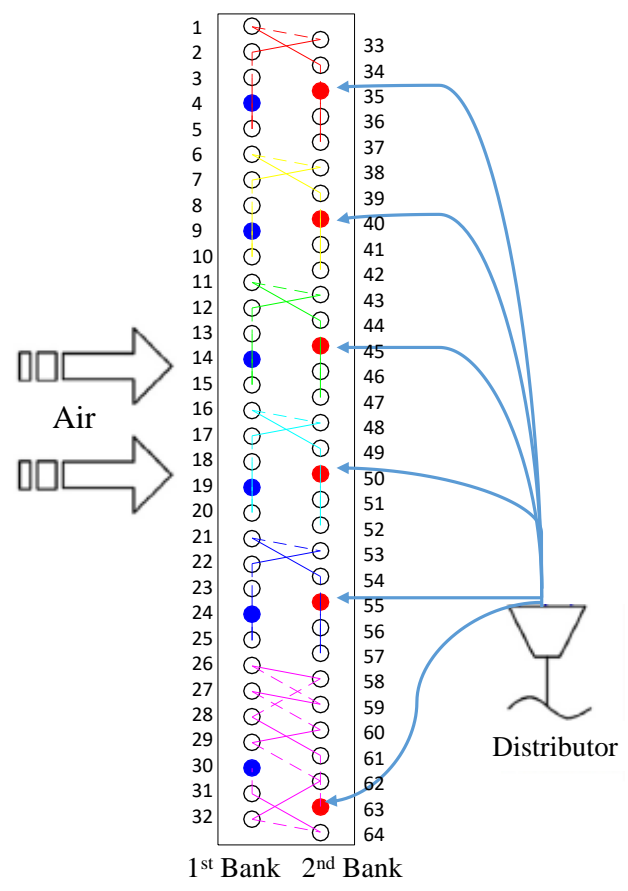

Figure 4. Optimal heat exchanger circuitry

Table 4 compares the steady state performance of the baseline and the optimal design. The optimal design has almost the same capacity as the baseline, while the refrigerant pressure drop yields a decrease from 59.6 $\mathrm{kPa}$ to $55.8 \mathrm{kPa}$ by $6.3 \%$. This is because the optimal circuitry in Figure 4 has 6 circuits without merging Ubends. However, the baseline (Figure 1) has six inlets and three outlets, so in each circuit two streams are merged into one. The high refrigerant pressure drop in baseline is induced by the large refrigerant mass flux at 
the downstream of each circuit. Despite the significant increase of superheat region length, the total outlet superheat of the baseline and the optimal design only varies within $1 \mathrm{~K}$, which is good to avoid refrigerant flooding in compressor. In Table 4, 'U-bends L1' and 'U-bends L2' indicate the number of U-bends which stretches across 1 tube row and 2 tube rows respectively. 'U-bends $\geq$ L3' is the number of long U-bends which stretches more than 2 tube rows. It can be seen that the optimal circuitry has acceptable manufacturability without long U-bends.

Table 4. Comparison of Baseline VS Optimal Design

\begin{tabular}{|l|l|l|}
\hline Case & Baseline & Optimal \\
\hline Capacity [W] & 7502 & 7514 \\
\hline Refrigerant DP [kPa] & 59.6 & 55.8 \\
\hline Outlet Superheat [K] & 10.4 & 11.3 \\
\hline Superheat length [\%] & 59.7 & 70.6 \\
\hline U-bends L1 & 55 & 40 \\
\hline U-bends L2 & 6 & 18 \\
\hline U-bends $\geq$ L3 & 0 & 0 \\
\hline
\end{tabular}

\section{Heat Exchanger Simulation under Frosting Conditions}

\subsection{Dynamic HX Model with Non-Uniform Frost Growth Prediction}

In order to evaluate the HX performance under frosting conditions, a distributed-parameter heat exchanger model (Qiao et al, 2015) implemented using Modelica language on Dymola 4.7 (Dassault Systemes, 2014) is used. This dynamic heat exchanger model is integrated with a detailed frost growth prediction model (Qiao et $a l, 2017)$ to account for non-uniform frost accumulation on a fan-supplied coil. The air flow redistribution is solved by linearizing a system of non-linear air pressure drop equalization equations. Readers are referred to original papers for details of the dynamic HX model and the frost growth model.

It is worth mentioning that this HX model as well as the frosting growth model were validated with measured data for the flash tank vapor injection heat pump cycle as described in section 2.3. Figure 5 shows the comparison between the dynamic simulation results and experimental data for this FTVI system in terms of HX capacity, power consumption and cycle COP. It can be seen that the HX model with frost growth model integrated can predict the transients of this system with reasonable accuracy under frosting conditions.

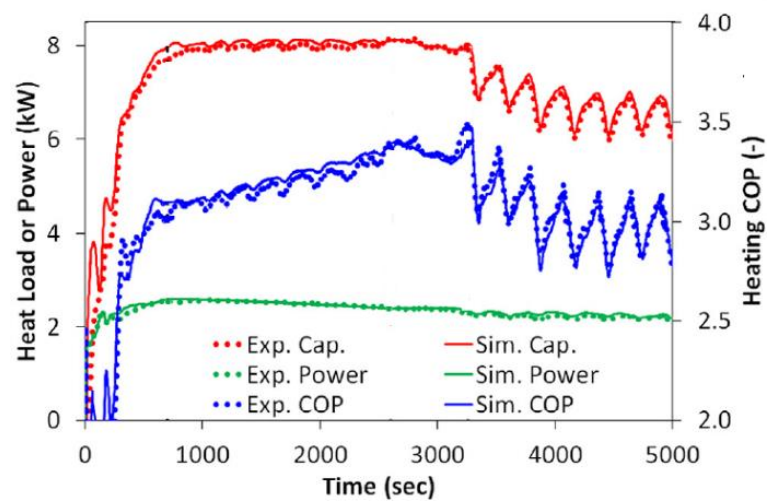

Figure 5. Frosting experiment tests vs simulations (Qiao et $a l, 2017)$

\subsection{Transient Simulation Results and Discussion}

In this section, the baseline and optimal circuitry designs are simulated for 6000 seconds frosting test. The adopted operating conditions is the same as those in Table 2 (ASHRAE, 2010).

Figure 6 compares the HX capacity between the baseline and optimal design. Both capacities decrease as frost accumulates on HX surface. However, the capacity of the baseline decreases faster than the optimal design, which ultimately yields a $11.6 \%$ capacity difference at the end of 6000s frosting test.

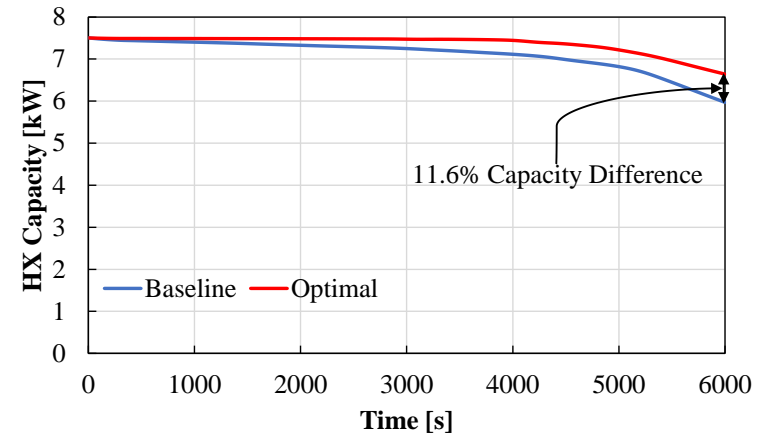

Figure 6. Evaporator capacity transients

Figure 7 shows the transients of the total frost mass accumulation on HX surface. At the early stage of the frosting test, the frost mass on the two HXs are very close. The frost mass starts to show noticeable difference after 3300 s and the difference ends up to be $5.1 \%$ at $6000 \mathrm{~s}(4.12 \mathrm{~kg}$ frost on the baseline and $3.91 \mathrm{~kg}$ frost on the optimal design).

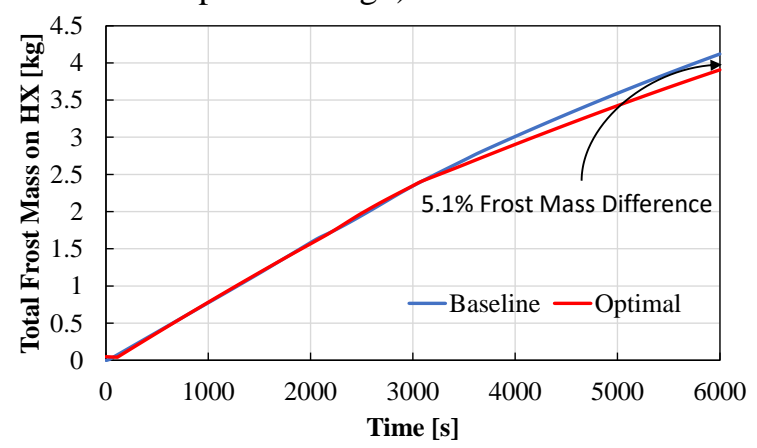

Figure 7. Frost mass transients 
Figure 8 presents the frost mass distribution on each tube bank of the two HXs. It is evident that the $1^{\text {st }}$ tube bank of the baseline has much faster frost accumulation rate. Although the frost growth rate for the $2^{\text {nd }}$ bank of the baseline is less than the frost growth rate of the $2^{\text {nd }}$ bank of the optimal design, it doesn't provide much benefit for the baseline, because the large amount of frost on the $1^{\text {st }}$ bank tends to dominate the air flow resistance of the entire coil. In fact, the slow frost growth on the $2^{\text {nd }}$ bank attributes to the insufficient air which can flow through the $1^{\text {st }}$ bank to reach the $2^{\text {nd }}$ bank.

In other words, despite the total frost growth rate on the two HXs are similar (Figure 7), the bank-wise frost distribution on the optimal circuitry is more uniform than that of the baseline (Figure 8).

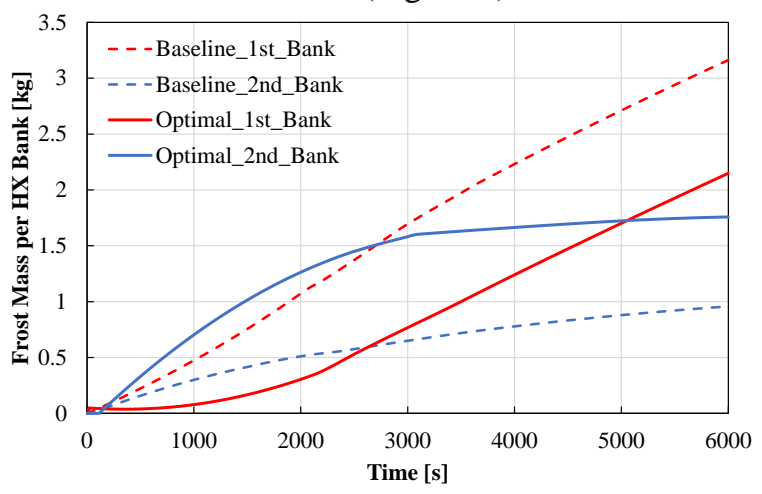

Figure 8. Frost distribution on different banks

Figure 9 and Figure 10 perform an in-depth observation on the frost distribution by presenting the time evolution of the frost thickness on each tube for the two HXs. It is prominent that the frost thickness on the tubes at the $1^{\text {st }}$ bank of optimal design (Figure 10, tube $\# 1$ to \#32) are much less than that of the baseline (Figure 9, tube \#1 to \#32). This indicates that in addition to the uniform bank-wise frost distribution, the optimal design also yields more uniform frost distribution on each tube. As listed in Figure 9 and Figure 10, at the end of the test (6000s), the standard deviation of frost thickness among all tubes is $0.22 \mathrm{~mm}$ for the baseline, while that of the optimal is only $0.13 \mathrm{~mm}$. This result implies that the proposed circuitry optimization approach can generate circuitry design with more uniform frost distribution.

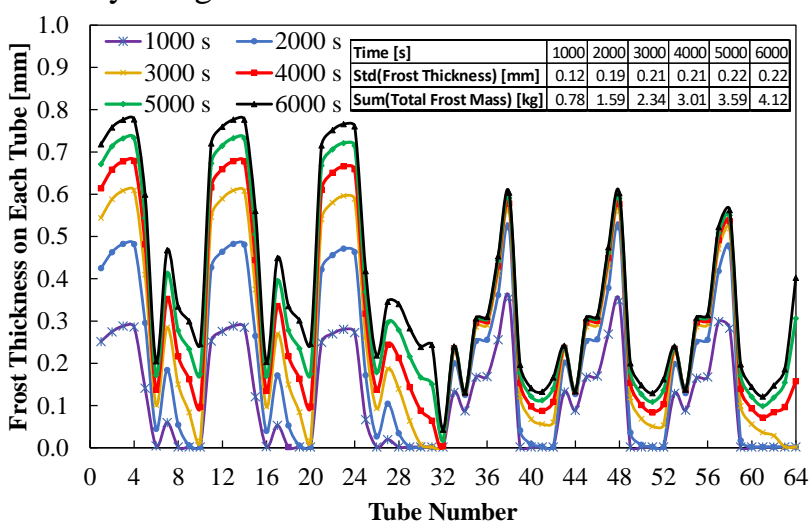

Figure 9. Evolution of per tube frost thickness (baseline)

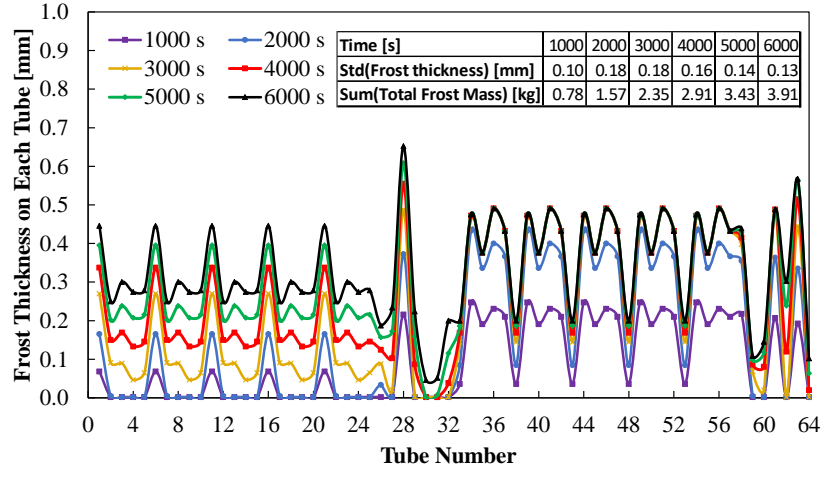

Figure 10. Evolution of per tube frost thickness (optimal)

Figure 11 shows the transients of the air volume flow rate during the frost buildup process. It can be seen that the air flow rate reduction of the baseline coil is substantially higher than that of the optimal design. The non-uniform frost distribution results in $16.7 \%$ air flow rate difference at the end of the frosting test. This reinforces the previous finding that the capacity merit of the optimal design attributes to the superior characteristics of the frost accumulation and the associated effect on the air side pressure drop.

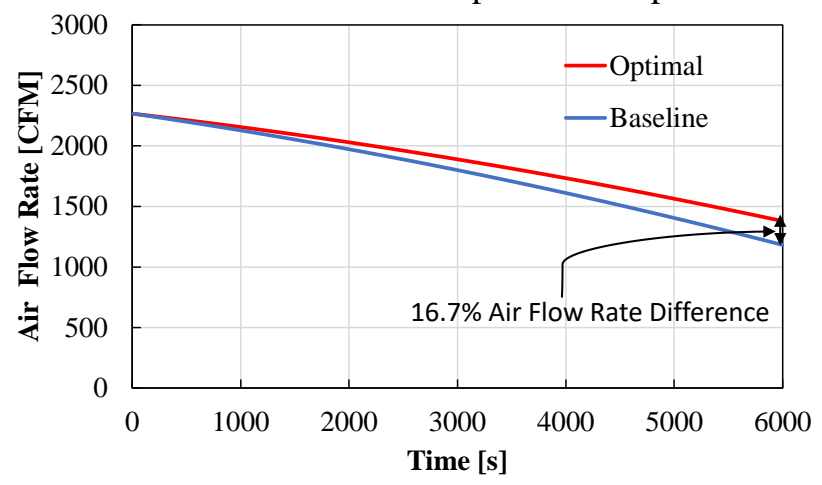

Figure 11. Transients of calculated air volume flow rate

\section{Conclusion}

This study proposes a novel TFHX circuitry optimization approach to obtain circuitry design with improved HX performance under frosting conditions. In order to verify the efficacy of the proposed approach, a dynamic HX model integrated with frost growth model is used to evaluate the performance of baseline and optimal circuitry designs. The results show that the optimal circuitry leads to a predicted $11.6 \% \mathrm{HX}$ capacity improvement and $5.1 \%$ frost mass reduction at the end of the 6000 seconds frosting test. Although the actual improvement from the optimal circuitry design needs to be further validated by manufacturing and testing the HX, these results demonstrate that the proposed approach has potential to generate circuitry designs with larger HX capacity, more uniform frost distribution and therefore longer evaporator operation time between defrost operations. 


\section{Acknowledgements}

This work was supported by the Modeling and Optimization Consortium at the University of Maryland.

\section{References}

Aljuwayhel, N., Reindl, D., Klein, S., and Nellis, G. (2007). Comparison of parallel-and counter-flow circuiting in an industrial evaporator under frosting conditions. International Journal of Refrigeration, 30(8), 1347-1357.

ASHRAE. (2010). Methods of testing for rating seasonal efficiency of unitary air conditioners and heat pumps. ANSI/ASHRAE Standard, Atlanta, GA, USA.

Blasius, H. (1907). Grenzschichten in Flüssigkeiten mit kleiner Reibung: Druck von BG Teubner.

Dassault Systemes (2014). Dymola 7.4.

Gnielinski, V. (1976). New equations for heat and mass transfer in turbulent pipe and channel flow. Int. Chem. Eng., 16(2), 359-368.

Jiang, H., Aute, V., and Radermacher, R. (2006). CoilDesigner: a general-purpose simulation and design tool for air-to-refrigerant heat exchangers. International Journal of Refrigeration, 29(4), 601-610.

Kim, N.-H., Yun, J.-H., and Webb, R. (1997). Heat transfer and friction correlations for wavy plate fin-and-tube heat exchangers. Journal of Heat Transfer, 119(3), 560-567.

Li, Z. and Aute, V. (2018). Optimization of Heat Exchanger Flow Paths Using a Novel Integer Permutation Based Genetic Algorithm. EngOpt 2018 Proceedings of the 6th International Conference on Engineering Optimization, Lisboa, Portugal.

Li, Z., Ling, J., and Aute, V. (2018). Tube-fin heat exchanger circuitry optimization using integer permutation based genetic algorithm. Paper presented at the 17th International Refrigeration and Air Conditioning Conference Purdue.

Malhammar, A. (1988). Monitoring frost growth in evaporators is a complex process. Australian Refrigeration, Air conditioning and Heat.

Müller-Steinhagen, H. and Heck, K. (1986). A simple friction pressure drop correlation for two-phase flow in pipes. Chemical Engineering and Processing: Process Intensification, 20(6), 297-308.

Ogawa, K., Tanaka, N., and Takeshita, M. (1993). Performance improvement of plate fin-and-tube heat exchangers under frosting conditions. Paper presented at the the 1993 Winter Meeting of ASHRAE Transactions. Part 1, Chicago, IL, USA, 01/23-27/93.

Qiao, H., Aute, V., and Radermacher, R. (2015). Transient modeling of a flash tank vapor injection heat pump systemPart I: Model development. International Journal of Refrigeration, 49, 169-182.

Qiao, H., Aute, V., and Radermacher, R. (2017). Dynamic modeling and characteristic analysis of a two-stage vapor injection heat pump system under frosting conditions. International Journal of Refrigeration, 84, 181-197.

Sanders, C. T. (1974). The influence of frost formation and defrosting on the performance of air coolers.

Shah, M. M. (2017). Unified correlation for heat transfer during boiling in plain mini/micro and conventional channels. International Journal of Refrigeration, 74, 606626. doi:10.1016/j.ijrefrig.2016.11.023

Xu, X., Hwang, Y., and Radermacher, R. (2013). Performance comparison of R410A and R32 in vapor injection cycles. International Journal of Refrigeration, 36(3), 892-903. 